Supporting information

\title{
Enhancement of Enzymatic Activity Using Microfabricated Poly(E-caprolactone)/Silica Hybrid Microspheres with Hierarchically Porous Architecture
}

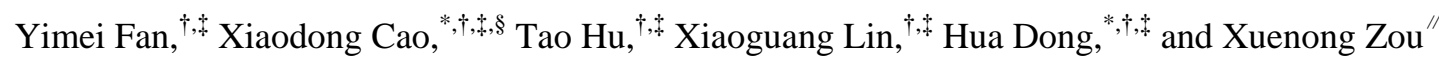

(1) Effect of PCL concentration on surface morphology of $\mathrm{PCL} / \mathrm{SiO}_{2}$ hybrid microsphere
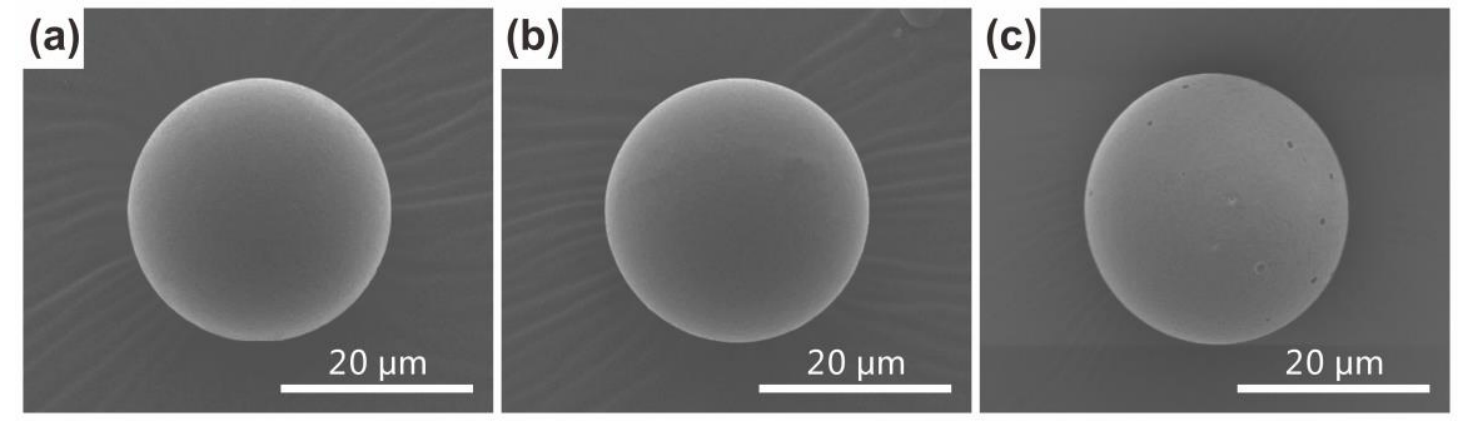

Fig. S1. Surface morphologies of $\mathrm{PCL} / \mathrm{SiO}_{2}$ hybrid microspheres fabricated using the dispersed phase containing $20 \mathrm{wt} \%$ TEOS and (a) $20 \mathrm{mg} / \mathrm{mL}$ of PCL, (b) $40 \mathrm{mg} / \mathrm{mL}$ PCL, (c) $60 \mathrm{mg} / \mathrm{mL}$ of PCL. The continuous phase and collection solution were aqueous solution containing $2 \mathrm{wt} \%$ of PVA.

(2) Effects of TEOS and ammonia concentrations on surface morphology of

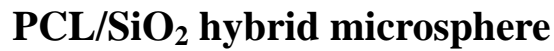




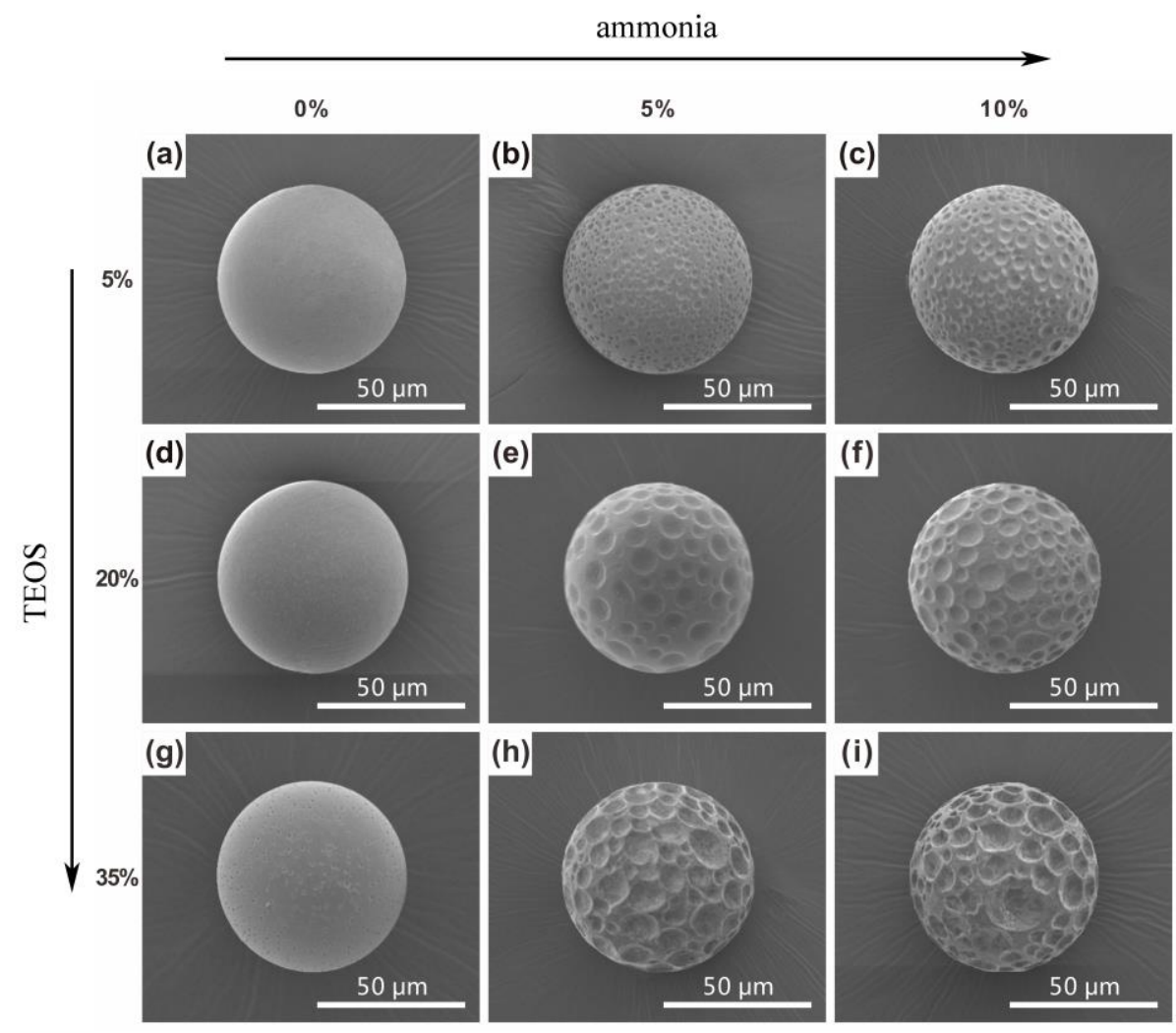

Fig. S2. Effects of TEOS concentration in the dispersed phase and ammonia concentration in the collection solution on surface morphology of $\mathrm{PCL} / \mathrm{SiO}_{2}$ hybrid microspheres. The PCL concentration in the dispersed phase was $40 \mathrm{mg} / \mathrm{mL}$.

(3) Effects of $\mathrm{SiO}_{2}$ and ethanol on surface morphology of $\mathrm{PCL} / \mathrm{SiO}_{2}$ hybrid microsphere
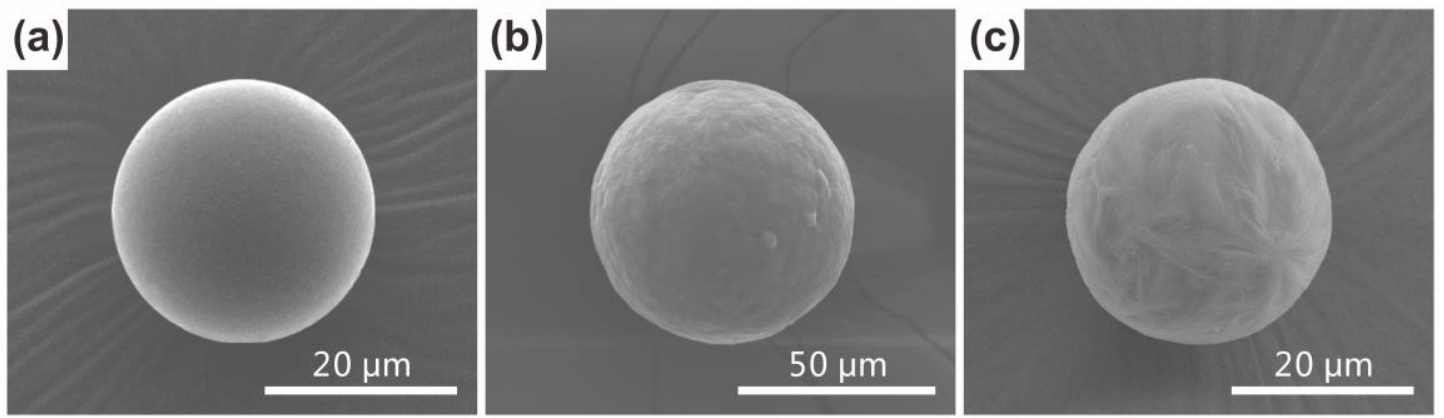

Fig. S3. SEM images of microspheres prepared with the dispersed phase containing (a) $40 \mathrm{mg} / \mathrm{mL}$ of PCL, (b) $40 \mathrm{mg} / \mathrm{mL}$ of PCL and $0.08 \mathrm{~g}$ of nano-SiO PCL and $5 \mathrm{~mL}$ of ethanol. The continuous phase and collection solution were aqueous solution containing $2 \mathrm{wt} \%$ of PVA. 
(4) Effect of $\mathrm{NaOH}$ in the continuous phase on morphology of microspheres
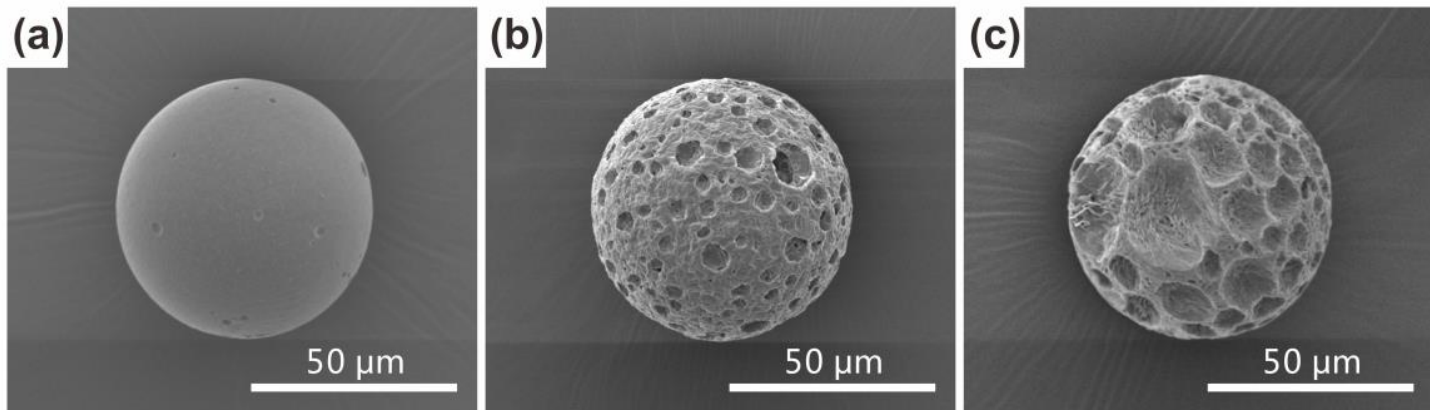

Fig. S4. SEM images of $\mathrm{PCL} / \mathrm{SiO}_{2}$ hybrid microspheres prepared with the dispersed phase containing $40 \mathrm{mg} / \mathrm{mL}$ of PCL and $20 \mathrm{wt} \%$ of TEOS, and the continuous phase containing $\mathrm{NaOH}$ instead of ammonia. $\mathrm{pH}$ value of the continuous phase was kept as (a) 7 , (b) 12 , (c) 12.6 .

(5) Structure and size distribution of PCL/SiO2 hybrid microspheres after activity/stability measurements
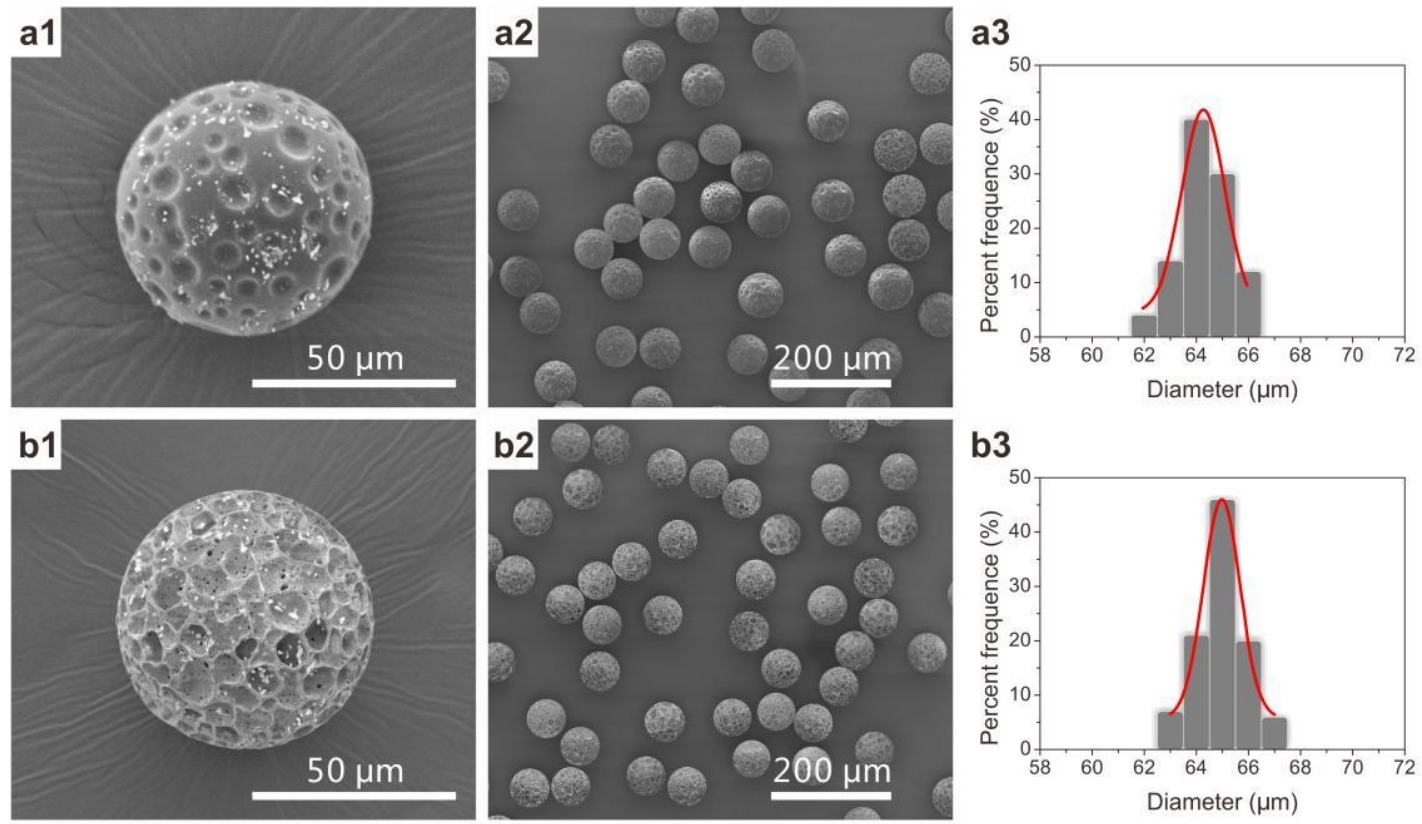

Fig. S5. SEM images and particle size distribution of $\mathrm{PCL} / \mathrm{SiO}_{2}$ hybrid microspheres after reusability assay for 8 cycles: (a) shallow pore, (b) deep pore. 


\section{References}

(18) Beck, J. S.; Vartuli, J. C.; Roth, W. J.; Leonowicz, M. E.; Kresge, C. T.; Schmitt, K. D.; Chu, C. T. W.; Olson, D. H.; Sheppard, E. W.; McCullen, S. B.; Higgins, J. B.; Schlenker, J. L., A new family of mesoporous molecular sieves prepared with liquid crystal templates. J. Am. Chem. Soc. 1992, 114, 10834-10843. 